\title{
Molecular fossils in Cretaceous condensate from western India
}

\author{
Sharmila Bhattacharya ${ }^{1, *}$, Suryendu Dutta ${ }^{1}$ and Ratul Dutta ${ }^{2}$ \\ ${ }^{1}$ Department of Earth Sciences, Indian Institute of Technology Bombay, Powai, Mumbai 400 076, India. \\ ${ }^{2}$ Geoscience Department, Oil India Limited, Jodhpur 342005 , Rajasthan, India. \\ ${ }^{*}$ Corresponding author. e-mail: sharmila.bhattacharya@iitb.ac.in
}

The present study reports the biomarker distribution of condensate belonging to the early Cretaceous time frame using gas chromatography-mass spectrometry (GC-MS). The early Cretaceous palaeoenvironment was inscribed into these molecular fossils which reflected the source and conditions of deposition of the condensate. The saturate fraction of the condensate is characterized by normal alkanes ranging from $n-\mathrm{C}_{9}$ to $n$ - $\mathrm{C}_{29}$ (CPI-1.13), cycloalkanes and $\mathrm{C}_{14}$ and $\mathrm{C}_{15}$ sesquiterpanes. The aromatic fraction comprises of naphthalene, phenanthrene, their methylated derivatives and cyclohexylbenzenes. Isohexylalkylnaphthalenes, a product of rearrangement process of terpenoids, is detected in the condensate. Several aromatic sesquiterpenoids and diterpenoids have been recorded. Dihydro-ar-curcumene, cadalene and ionene form the assemblage of sesquiterpenoids which are indicative of higher plant input. Aromatic diterpenoid fraction comprises of simonellite and retene. These compounds are also indicative of higher plants, particularly conifer source which had been a predominant flora during the Cretaceous time.

\section{Introduction}

Condensate is liquid hydrocarbon of low density and high API gravity which remains in the gaseous state in the ground and condenses at lower depths (Hunt 1996). The condensation from gaseous to liquid phase is controlled by the temperature and pressure conditions in the reservoir. In condensates, liquid hydrocarbon remains dissolved in gaseous phase and fractionates out of the solution when the pressure drops below dew point. The separation into liquid hydrocarbons occurs through retrograde condensation. Previously, it was supposed that condensates are derived from resinites at low levels of maturity (Snowdon and Powell 1982). However, hydrous pyrolysis experiments resulted in pyrolyzates with entirely different composition than what is observed in natural condensates (Hwang and Teerman 1988). Condensates may originate by several means - from kerogen as an intermediate product between oil and gas, conversion of oil to gas in a reservoir, and/or from gas phase migration of hydrocarbons out of an oil pool because of physical phenomena such as vaporization or gas stripping (Hunt 1996). Broadly, two types of gas-condensate systems can be distinguished. Firstly, condensates produced directly from source rock and secondly, those which are formed by transformation of petroleum (Botneva et al. 1990). Condensates may be enriched in paraffin compounds. Condensates rich in naphthenic and aromatic compounds may be formed by evaporative fractionation (Thompson 1987). The time frame of the present study, the early Cretaceous period, was crucial in the geological history of the Indian continent. During the bulk of the Jurassic period, India remained as a component of the southern supercontinent Gondwana.

Keywords. Cretaceous; condensate; Jaisalmer basin; biomarkers; conifer source. 
Rifting plausibly began at the tail end of Jurassic (Briggs 2003). The Cretaceous period witnessed the voyage of India from the southern hemisphere towards north. There had been speculations that India persisted as an island continent during the Cretaceous, which were refuted on several occasions (Chatterjee and Hotton 1986; Briggs 2003). The Cretaceous period was warm and switched between arid and humid conditions (Föllmi 2012). The Jurassic-Cretaceous periods were dominated by gymnosperm flora, particularly conifers, which formed the most diverse group during that time. The huge reserves of terrigenous-source derived petroleum of the Jurassic-Cretaceous periods were fed by the coniferous plants to a large extent (Shanmugam 1985; Philp and Gilbert 1986). Biomarkers have been analyzed in order to understand the source organic matter. These are robust molecules, mostly lipids, which traverse a long journey from the biosphere to the geosphere after the demise of organisms and are recorded in rocks as chemical fossils (Brocks and Pearson 2005). The present work manifests the organic geochemical characteristics of the condensate recovered from the Pariwar Formation belonging to early Cretaceous age, Jaisalmer basin and sheds light on the precursor and palaeoenvironmental features.

\section{Regional geology and stratigraphy}

The Jaisalmer basin had developed as a pericratonic basin in the Rajasthan continental margin (Valdiya 2010). The most prominent and crucial sequence of this basin is the Mesozoic sequence commencing with Shumarwali Formation in the Triassic to the Parh Formation in the Cretaceous (Krishna 1987). Sedimentation in the Triassic began in a fluvial to deltaic environment. The early Jurassic environment was intertidal to neritic and the time window witnessed several cycles of carbonate depositions on stable shelf (Valdiya 2010). There were several phases of transgression and regression during the Cretaceous which induced the deposition of marine and deltaic sediments (Verma et al. 2012). The Mesozoic condensate in the present study has been recovered from the Lower Cretaceous Pariwar Formation. The Pariwar Formation represents regression with shallow marine and brackish conditions towards the lower part and complete regression with the setting in of continental condition towards the top (http://www.dghindia.org/23.aspx). Palynomorph and foraminifera studies indicate earlier part of early Cretaceous age for the Pariwar Formation (Valdiya 2010 and references therein). Further details of the geology and stratigraphy of the area cannot be provided due to proprietary reasons.

\section{Samples and methods}

\subsection{Sample preparation}

Condensate sample has been collected from a well in Jaisalmer basin, Rajasthan. The condensate sample, an assemblage of several compounds, is separated into saturate and aromatic fractions with the aid of column chromatography. The glassware used is sterilized with methanol and dichloromethane and fired at $300^{\circ} \mathrm{C}$ for 4 hours. Activated silica gel (100-200 mesh) is filled in a column and the condensate sample then added on it and allowed to dry overnight. The experiment commenced with the measurement of dead volume (DV) with $n$-hexane. Dead volume is the volume of solvent ( $n$-hexane) added that completely soaked the silica gel. $n$-Hexane is added further $(3 / 8$ of dead volume) in order to elute the complete saturate fraction from the sample. A solution of $n$ hexane and dichloromethane is prepared in a proportion of 4:1 of $4 \mathrm{DV}$. This is added to the sample in order to elute the aromatic fraction. The saturate and aromatic fractions are analyzed with gas chromatography-mass spectrometry.

\subsection{Gas chromatography-mass spectrometry}

The sample has been analyzed using an Agilent 5975 mass spectrometer interfaced to a 7890 gas chromatograph. The gas chromatograph is fitted with a DB-1 fused silica capillary column $(30 \mathrm{~m} \times$ $0.25 \mathrm{~mm}$ i.d., $\times 0.25 \mu \mathrm{m}$ film thickness). Helium is used as carrier gas. The flow rate is $1 \mathrm{ml} / \mathrm{min}$. The saturate and aromatic fractions are analyzed in full scan mode. Full scan analyses are conducted over a mass range of 50-600 Da. The sample is dissolved in $n$-hexane and injected by autosampler in pulsed splitless mode. The ion source operates in the electron ionization mode at $70 \mathrm{ev}$. The temperature of $\mathrm{GC}$ oven is held at $40^{\circ} \mathrm{C}$ (for $5 \mathrm{~min}$ ) and then ramped to $310^{\circ} \mathrm{C}$ at $4^{\circ} \mathrm{C} / \mathrm{min}$ and held for $5.5 \mathrm{~min}$. Identification of compounds is based on comparison of elution pattern and mass spectra with those reported in the literature. Data have been processed using Chemstation software.

\section{Results and discussions}

\subsection{Saturate hydrocarbons}

The total ion chromatogram of the saturate fraction is presented in figure 1.

\subsubsection{Acyclic compounds}

The saturate fraction is dominated by normal alkanes ranging from $n-\mathrm{C}_{9}$ to $n-\mathrm{C}_{29}$. The distribution 


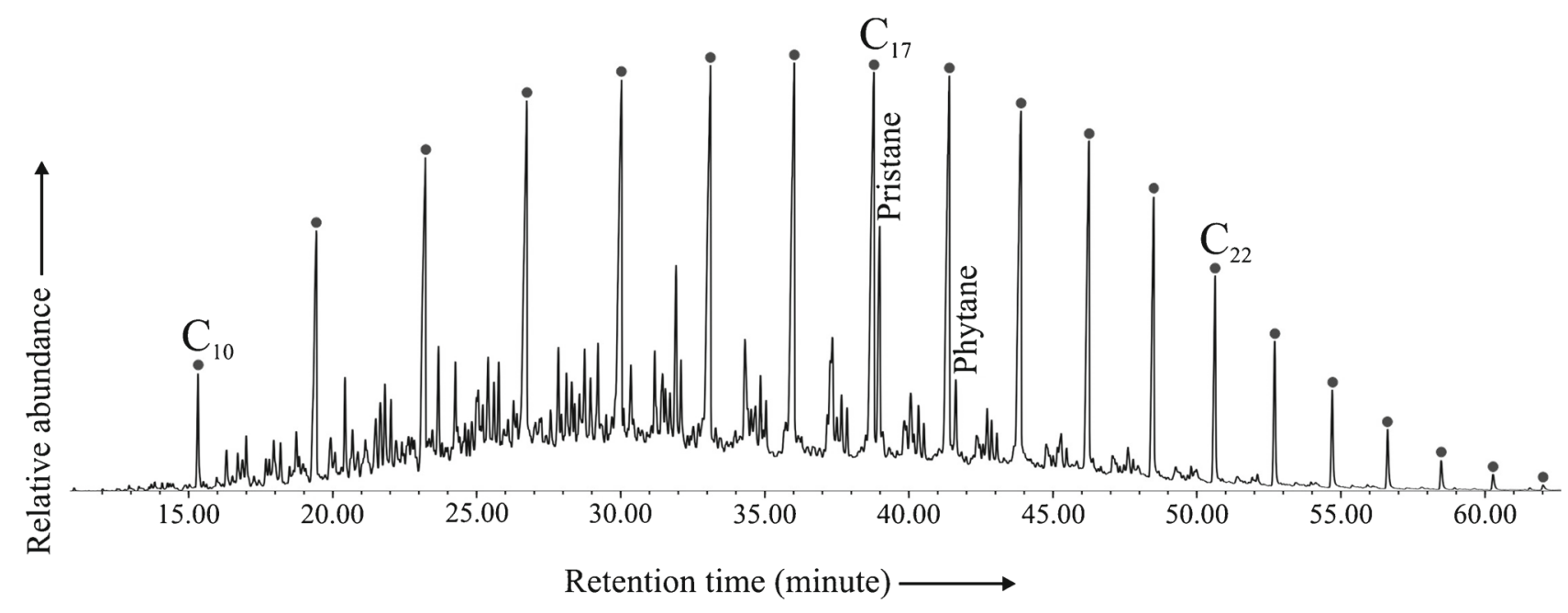

Figure 1. Total ion chromatogram of aliphatic fraction of the condensate of Cretaceous age from a well, Jaisalmer basin, western India. The solid circles indicate normal alkanes. Carbon numbers of $n$-alkanes are indicated.

of the normal alkanes is unimodal. A progressive rise from $n-\mathrm{C}_{10}$ to $n-\mathrm{C}_{16}$ and a gradual decrease thereafter up to $n-\mathrm{C}_{29}$ is clearly observed in $m / z$ 57. $n-\mathrm{C}_{12}$ to $n-\mathrm{C}_{15}$ are the dominant peaks in $m / z$ 57. The normal alkane distribution displays odd carbon preference beyond $n-\mathrm{C}_{20}$ and is consistent with the CPI value which is 1.13 (Marzi et al. 1993). The distribution of normal alkanes, particularly abundant in the $\mathrm{C}_{12}{ }^{-}$ $\mathrm{C}_{15}$ range, may suggest algal/bacterial input into the organic matter. Pristane and phytane are the major acyclic isoprenoids present in the condensate. There are several conjectures regarding the source of these acyclic compounds. The most usual source is believed to be the phytyl side chain of chlorophyll or bacteriochlorophyll (Brooks et al. 1969; Powell and McKirdy 1973). Archaea have also been supposed to be a source of pristane and phytane (Chappe et al. 1982). It has been postulated that catagenetic decomposition of methyltrimethyl-tridecylchromans might also produce pristane ( $\mathrm{Li}$ et al. 1995). The pristane and phytane in the condensate is probably derived from higher plant chlorophyll or bacteriochlorophyll since signatures of archaea or tocopherols are not recorded. The pristane/phytane ratio is 3.86. The high pristane/phytane ratio is indicative of oxic to suboxic condition of deposition (Peters et al. 2005). The values of pristane $/ n-\mathrm{C}_{17}$ and phytane $/ n-\mathrm{C}_{18}$ are 0.37 and 0.09 , respectively.

\subsubsection{Cycloalkanes}

A homologous series of $n$-alkylcyclohexane $(\mathrm{m} / z$ 83) ranging from butyl cyclohexane to heptadecyl cyclohexane, maximizing at heptylcyclohexane, is observed. Another series of monocyclic alkanes identified as methyl- $n$-alkylcyclohexane $(\mathrm{m} / \mathrm{z}$ $97)$ is detected in the condensate. The series ranges from methyl- $n$-propyl-cyclohexane to methyl- $n$-hexadecyl-cyclohexane. Methyl- $n$-hexylcyclohexane is the most abundant among the other homologues. The homologous series of methyl- $n$ alkylcyclohexane can have three possible isomers 1,$2 ; 1,3 ; 1,4$ (Fowler and Douglas 1984). In the present sample, probably all the three possible isomers are present since homologous triplets can be observed. However, at $m / z 97$, the homologous series display triplets very clearly in the range methyl- $n$-propyl-cyclohexane to methyl$n$-heptyl-cyclohexane. The triplets beyond this range become obscure. The first member of the triplets is the most prominent and hence the most abundant isomer. $n$-alkylcyclohexanes and methyl- $n$-alkylcyclohexanes are possibly derived from the diagenetic alteration of algal fatty acids (Fowler et al. 1986). It has been proposed that $n$-alkylcyclohexanes might also be derived from bacterial lipid since their probable precursor is observed in thermo acidophilic bacterium (Fowler and Douglas 1984). Hence, both algal and bacterial origins of $n$-alkylcyclohexanes have been supposed. The reaction probably proceeds with the thermolysis of the heavy chained fatty acids into lighter chain $n$-alkanes and olefins. The reaction proceeds with the cyclization of olefinic radicals into the alkylcyclohexanes (Kissin 1990). However, the other confirmed signatures of algae such as steranes are not detected in the condensate. $\mathrm{C}_{29}$ and $\mathrm{C}_{30}$ hopanes are detected in considerably low abundance in an overloaded condensate sample.

\subsubsection{Sesquiterpenoids}

The distribution of saturate sesquiterpenoids is presented in figure 2 and peak numbers are listed in table 1. 


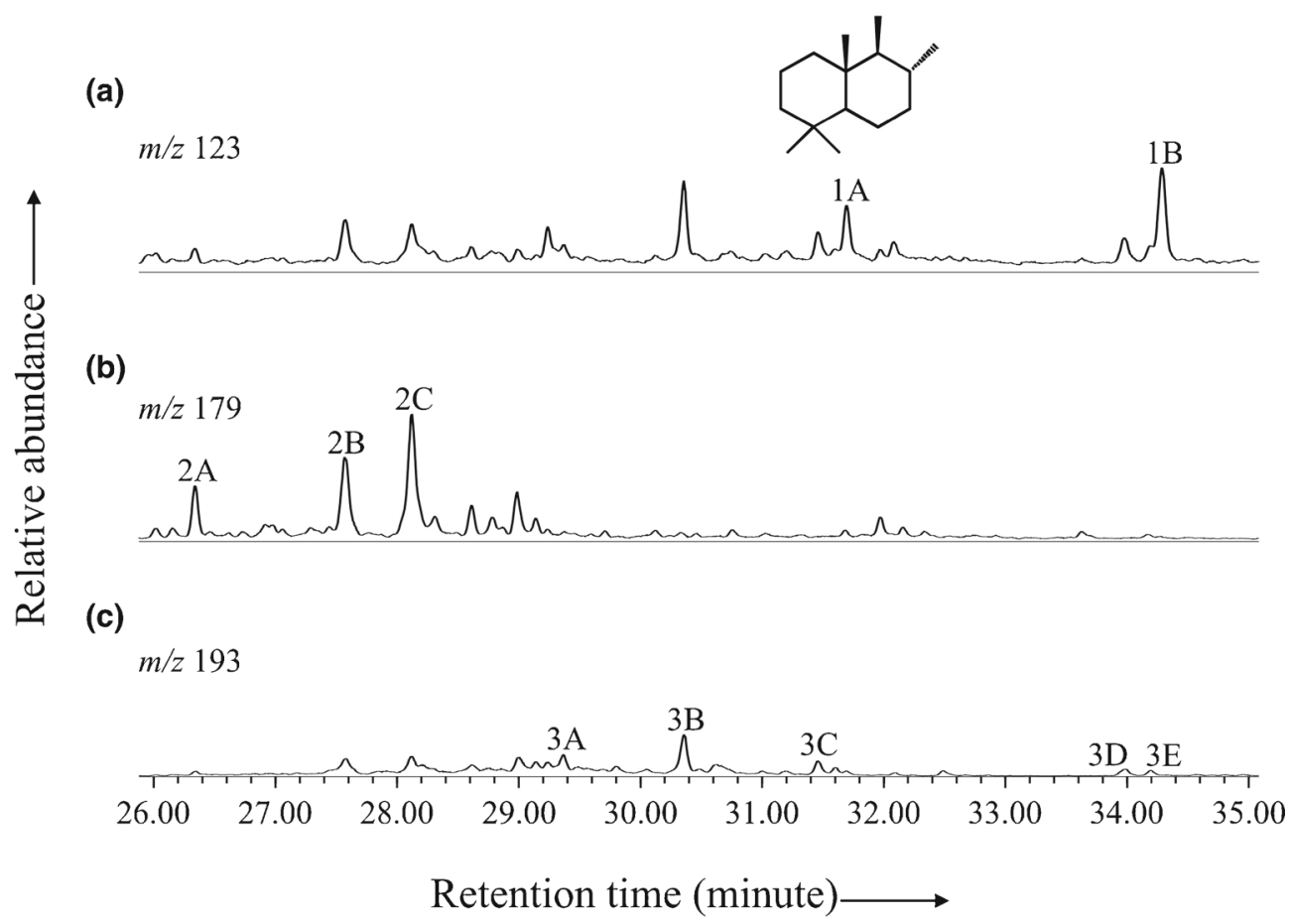

Figure 2. Partial mass chromatograms depicting the distributions of sesquiterpenoids (a) compounds bearing drimanerelated skeletons $(m / z 123)$, (b) $\mathrm{C}_{14}$ rearranged bicyclic alkanes $(m / z 179)$ and $(\mathbf{c}) \mathrm{C}_{15}$ rearranged bicyclic alkanes $(m / z$ 193) in the saturate fraction of condensate of Cretaceous age from a well, Jaisalmer basin, western India. Peak numbers are listed in table 1.

Table 1. Peak identifications, base peaks and molecular ions of saturate sesquiterpenoid compounds present in the Cretaceous condensate recovered from a well, Jaisalmer basin, western India.

\begin{tabular}{lccl}
\hline Peak no. & $\begin{array}{c}\text { Base } \\
\text { peak }\end{array}$ & $\begin{array}{c}\text { Molecular } \\
\text { ion }\end{array}$ & \multicolumn{1}{c}{ Compound name } \\
\hline 1A & 123 & 208 & Drimane \\
1B & 123 & 222 & Homodrimane \\
2A & 179 & 194 & $\mathrm{C}_{14}$ rearranged bicyclic alkane \\
2B & 179 & 194 & $\mathrm{C}_{14}$ rearranged bicyclic alkane \\
2C & 179 & 194 & $\mathrm{C}_{14}$ rearranged bicyclic alkane \\
3A & 193 & 208 & $\mathrm{C}_{15}$ rearranged bicyclic alkane \\
3B & 193 & 208 & $\mathrm{C}_{15}$ rearranged bicyclic alkane \\
3C & 193 & 208 & $\mathrm{C}_{15}$ rearranged bicyclic alkane \\
3D & 193 & 208 & $\mathrm{C}_{15}$ rearranged bicyclic alkane \\
3E & 193 & 208 & $\mathrm{C}_{15}$ rearranged bicyclic alkane \\
\hline
\end{tabular}

A homologous series of bicyclic alkanes with the drimane skeleton is identified from mass spectral data. $\mathrm{C}_{14}$ Nordrimane (mass fragments 109, $194)$ is observed which probably formed due to removal of a methyl group at the A ring of the drimane skeleton. $\mathrm{C}_{15}$ bicyclic sesquiterpane (drimane) is recorded in the sample which is further followed by an extended series of homodrimanes ranging from $\mathrm{C}_{16}$ to $\mathrm{C}_{20}$. However, $\mathrm{C}_{17}$ homodrimane is not observed. They might be derived from sesquiterpenoid precursors present in higher plants (Alexander et al. 1984). It is also believed that these compounds might be derived by the diagenesis of hopanoid precursors (Alexander et al. 1984; Wang et al. 1990). The possibility of tricyclic terpanes being the precursor of these bicyclic terpanes cannot be ruled out (Dimmler et al. 1984).

Apart from drimane and homodrimanes, other $\mathrm{C}_{14}$ sesquiterpanes are recorded in the sample. These compounds with base peaks 179 and 193 are $\mathrm{C}_{14}$ and $\mathrm{C}_{15}$ bicyclic sesquiterpanes, respectively (Alexander et al. 1984). These compounds are probably derived from drimane or drimane related precursors. There are three peaks with base peak 179 and molecular ion 194 which are probably isomers of A-nordrimane resulting from the loss of 
methyl group from the A-ring (Weston et al. 1989). Two prominent peaks and three minor peaks with base peak 193 and molecular ion 208 have been observed which might be isomers of rearranged drimane where there has been a shift in methyl group from one location to another. The rearrangement process is plausibly acid catalyzed (Weston et al. 1989).

\subsubsection{Diamondoids}

Diamondoids have been detected in the studied sample (figure 3; table 2). The isomers have been identified and listed based on the works of Fang et al. (2012). Diamondoids are cage-like rigid three dimensional molecules comprising fused ring alkanes whose structures are similar to diamonds. They may be conceived as truncated diamonds whose dangling bonds are terminated with hydrogen atom (Ali Mansoori 2007). Direct diamondoid precursors have not been observed in nature yet. However, these compounds are plausibly formed by the isomerization and rearrangement of polycyclic hydrocarbons, which in turn are generated by organisms, in the presence of a Lewis acid (Petrov et al. 1974). Artificial maturation of these sediments in the presence of mineral acids like montmorillonite, acidic aluminosilicate and calcium carbonate, was carried out. It was observed that along with other biomarkers, diamondoids were formed with the thermal maturity of the organic matter. It is worth mentioning that presence of montmorillonite facilitated the generation of diamondoids whereas calcium carbonate has an inhibition effect on it. In the present study, adamantane and its methylated as well as ethylated derivatives have been recorded whereas other diamondoids like diamantane, triamantane and higher polymantanes are not observed.

\subsection{Aromatic hydrocarbons}

Apart from alkylated benzenes, naphthalenes, phenanthrenes and their methylated counterparts which are ubiquitous in all kinds of samples, several other aromatic compounds are recorded in the sample providing further insights to the organic matter input and depositional condition.

\subsubsection{Cyclohexylbenzenes}

Cyclohexylbenzene and cyclohexylbenzene with one methyl substituent have been recorded in the sample. Structurally related biphenyls have also been observed. Two peaks are observed at $m / z 174$. Based on the elution pattern presented in the chromatogram published by Alexander et al. (1994a), (a)

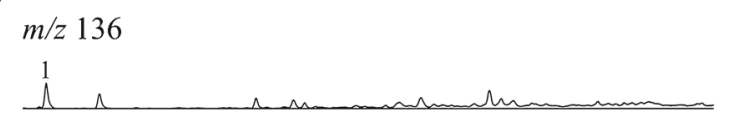

(b)

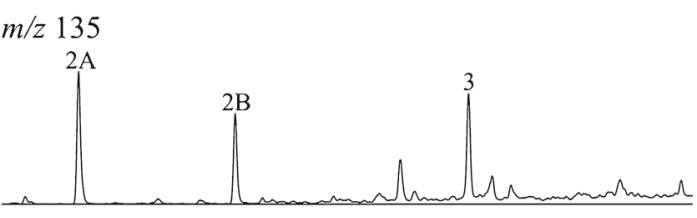

(c) $m / 2149$

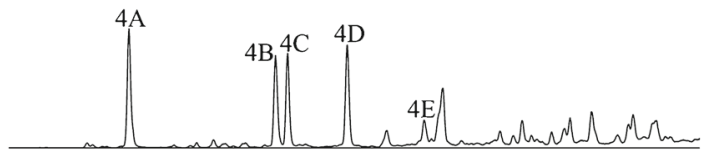

(d) $m / z 163$

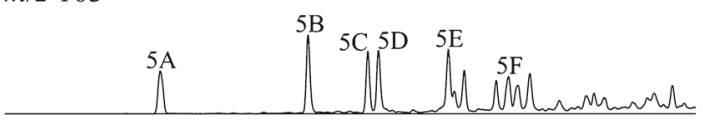

(e)

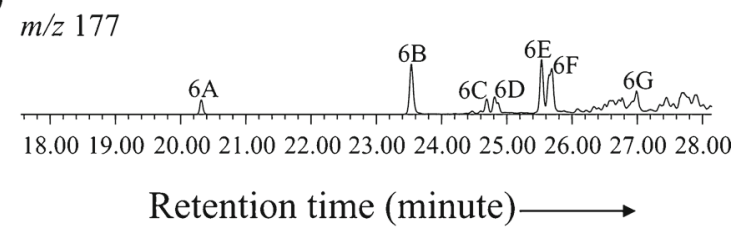

Figure 3. Partial mass chromatograms presenting the distributions of (a) adamantane $(\mathrm{m} / z$ 136), (b) methyl- and ethyladamantane $(\mathrm{m} / z$ 135), (c) dimethyl adamantane $(\mathrm{m} / z$ 149), (d) trimethyl adamantane $(m / z 163)$ and (e) tetramethyl adamantane $(\mathrm{m} / z$ 177) in the saturate fraction of condensate of Cretaceous age from a well, Jaisalmer basin, western India. Peak numbers are listed in table 2.

the first peak corresponds to an amalgamation of cyclohexyl-3-methyl benzene and cyclohexyl-2methyl benzene. The second peak corresponds to cyclohexyl-4-methyl benzene. The origin of these compounds in petroleum is not very clear since they occur in crude oils from various types of source material and geological ages. The genesis of these bicyclic ring systems might occur through phenol coupling of precursor compound at oxidizing condition (Alexander et al. 1994a).

\subsubsection{Isohexylalkylnaphthalenes}

A homologous series of isohexylalkylnaphthalenes $(\mathrm{m} / z 155,169,183,197,211)$ is observed (figure 4) and the peaks are listed in table 3. Five isohexylalkylnaphthalene peaks have been identified by tallying the mass spectra of these peaks with those published by Ellis et al. (1996). These compounds are probably produced by aromatization 
Table 2. Peak identifications, base peaks and molecular ions of diamodoid compounds (adamantane and methylated adamantanes) present in the saturate fraction of the Cretaceous condensate recovered from a well, Jaisalmer basin, western India.

\begin{tabular}{|c|c|c|c|}
\hline Peak no. & $\begin{array}{l}\text { Base } \\
\text { peak }\end{array}$ & $\begin{array}{l}\text { Molecular } \\
\text { ion }\end{array}$ & Compound name \\
\hline 1 & 93 & 136 & Adamantane \\
\hline $2 \mathrm{~A}$ & 135 & 150 & 1-Methyladamantane \\
\hline $2 \mathrm{~B}$ & 135 & 150 & 2-Methyladamantane \\
\hline 3 & 135 & 164 & Ethyladamantane \\
\hline $4 \mathrm{~A}$ & 149 & 164 & 1,3-Dimethyladamantane \\
\hline $4 \mathrm{~B}$ & 149 & 164 & 1,4-Dimethyladamantane(cis) \\
\hline $4 \mathrm{C}$ & 149 & 164 & 1,4-Dimethyladamantane(trans) \\
\hline $4 \mathrm{D}$ & 149 & 164 & 1,2-Dimethyladamantane \\
\hline $4 \mathrm{E}$ & 149 & 164 & 2,6 - + 2,4-Dimethyladamantane \\
\hline $5 \mathrm{~A}$ & 163 & 178 & 1,3,5-Trimethyladamantane \\
\hline $5 \mathrm{~B}$ & 163 & 178 & 1,3,6-Trimethyladamantane \\
\hline $5 \mathrm{C}$ & 163 & 178 & 1,3,4-Trimethyladamantane( cis) \\
\hline $5 \mathrm{D}$ & 163 & 178 & 1,3,4-Trimethyladamantane $($ trans $)$ \\
\hline $5 \mathrm{E}$ & 163 & 178 & 1,2,3-Trimethyladamantane \\
\hline $5 \mathrm{~F}$ & 163 & 178 & Unknown isomer of trimethyladamantane \\
\hline $6 \mathrm{~A}$ & 177 & 192 & 1,3,5,7-Tetramethyladamantane \\
\hline $6 \mathrm{~B}$ & 177 & 192 & 1,2,5,7-Tetramethyladamantane \\
\hline $6 \mathrm{C}$ & 177 & 192 & Unknown isomer of tetramethyladamantane \\
\hline $6 \mathrm{D}$ & 177 & 192 & 1,3,5,6-Tetramethyladamantane \\
\hline $6 \mathrm{E}$ & 177 & 192 & 1,2,3,5-Tetramethyladamantane \\
\hline $6 \mathrm{~F}$ & 177 & 192 & 1-Ethyl-3,5,7-trimethyladamantane \\
\hline $6 \mathrm{G}$ & 177 & 192 & Unknown isomer of tetramethyladamantane \\
\hline
\end{tabular}

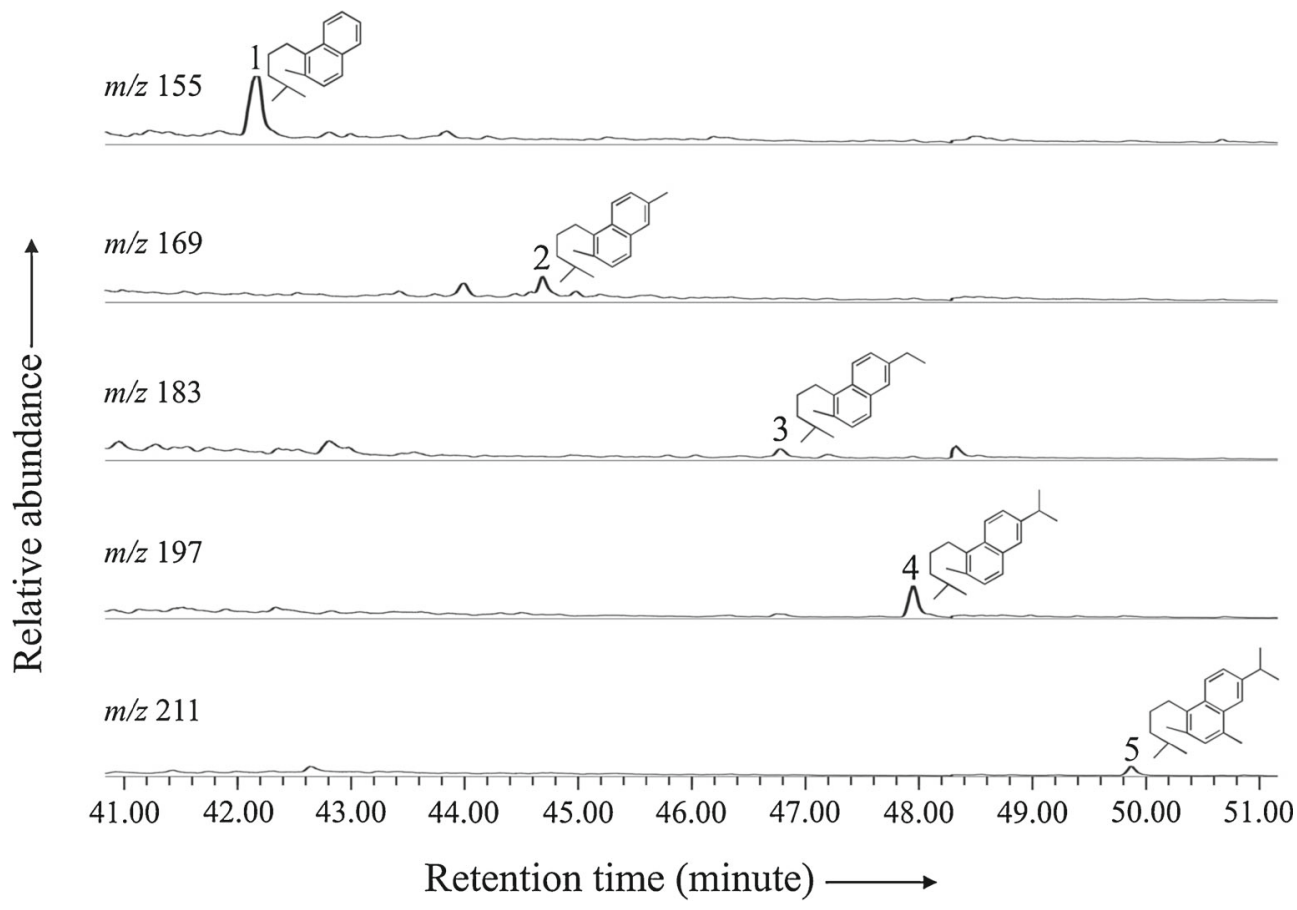

Figure 4. Partial mass chromatograms $(m / z 155,169,183,197,211)$ presenting the distributions of homologous series of isohexylalkylnaphthalenes (with molecular structures) in the aromatic fraction of condensate of Cretaceous age from a well, Jaisalmer basin, western India. Peak numbers are listed in table 3. 
Table 3. Peak identifications, base peaks and molecular ions of isohexylalkylnaphthalene compounds present in the aromatic fraction of the Cretaceous condensate recovered from a well, Jaisalmer basin, western India.

\begin{tabular}{lccl}
\hline Peak no. & $\begin{array}{c}\text { Base } \\
\text { peak }\end{array}$ & $\begin{array}{c}\text { Molecular } \\
\text { ion }\end{array}$ & \multicolumn{1}{c}{ Compound name } \\
\hline 1 & 155 & 226 & 2-methyl-1-(4-methylpentyl)naphthalene \\
2 & 169 & 240 & 2,6-dimethyl-1-(4-methylpentyl)naphthalene \\
3 & 183 & 254 & 6-ethyl-2-methyl-1-(4-methylpentyl)naphthalene \\
4 & 197 & 268 & 6-isopropyl-2-methyl-1-(4-methylpentyl)naphthalene \\
5 & 211 & 282 & 6-isopropyl-2,4-dimethyl-1-(4-methylpentyl)naphthalene \\
\hline
\end{tabular}

(a)

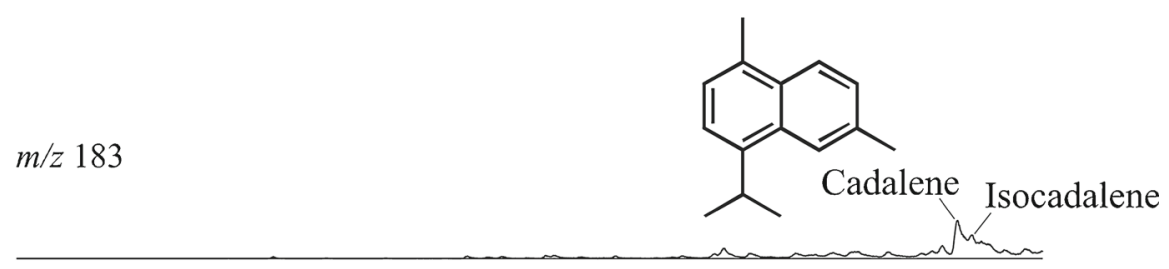

(b)

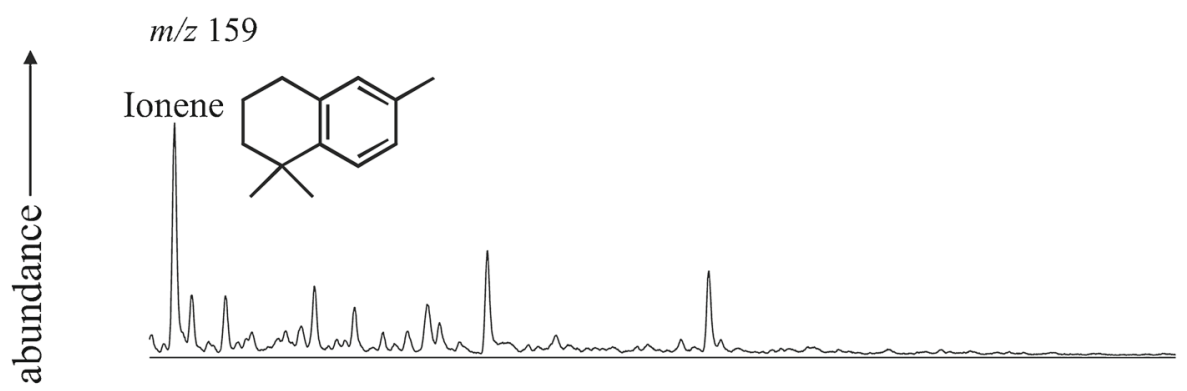

(c)

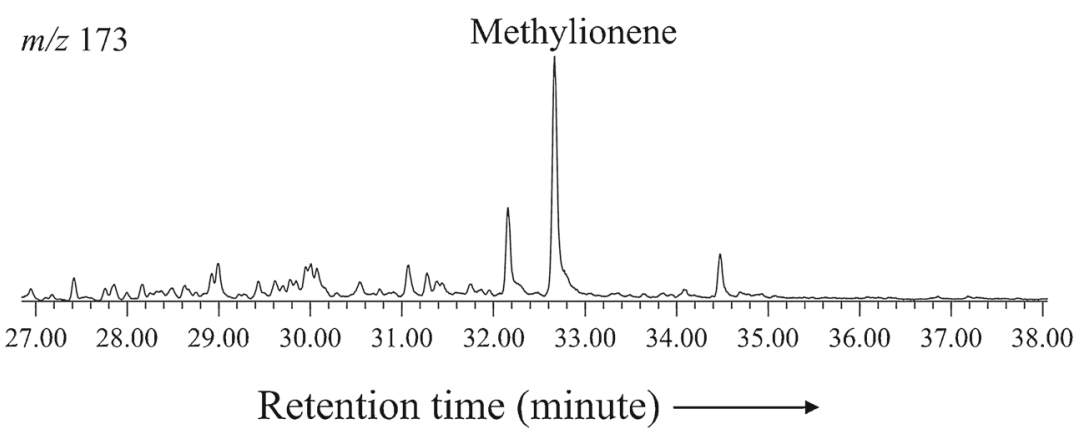

Figure 5. Partial mass chromatograms depicting the distributions of sesquiterpenoids (a) cadalene and isocadalene $(m / z$ 183), (b) ionene $(\mathrm{m} / z$ 159) and (c) methyl-ionene $(\mathrm{m} / z$ 173) in the aromatic fraction of condensate of Cretaceous age from a well, Jaisalmer basin, western India.

and rearrangement processes during diagenesis. The plausible reaction mechanism is described in Ellis et al. (1996). The fundamental conditions required for the reactions to proceed are the presence of an A/B ring system with a gemdimethyl group in the A-ring at C-4, a methyl group at C-10 and an unsaturated B-ring. A shift of methyl group occurs from C-10 to C-5 along with opening of the A-ring thereby generating an isohexyl chain. The B-ring gets aromatized. Laboratory experiments were conducted by Ellis et al. (1996) with non-aromatic diterpenoids and triterpenoids, which when heated under controlled conditions generated these compounds alongside other relevant compounds. The precursor compounds employed were labdan-8, 15-diol, phyllocladene and olean-18-ene. It is clearly evident that labdan-8, 15-diol and olean-18-ene produce 
isohexylalkylbenzenes which are not observed in the present sample. Phyllocladene generates isohexylalkylnaphthalenes. However, higher plant diterpenoids and triterpenoids cannot always be colligated with isohexylalkylnaphthalenes since genesis of these compounds is fraught with uncertainties. For instance, the opening of ring $\mathrm{A}$ is not favoured in the presence of oxygenated functional groups in the A-ring. However, the process moves on with ease in the presence of a gem-dimethyl group in ring A. Considering the presence of other aromatic diterpenoids in the present sample like cadalene, simonellite and retene, it is credible that the isohexylalkylnaphthalenes might be modified products of higher plant diterpenoids.

\subsubsection{Sesquiterpenoids}

The chromatograms of the following aromatic sesquiterpenoids are provided in figure 5 .

Aromatic monocyclic sesquiterpenoid, dihydroar-curcumene is observed in the present sample. In spite of being an aromatic compound, it elutes in the saturate fraction plausibly because of low polarity. A single peak of dihydro-ar-curcumene is observed from the chromatogram. However, the enantiomers $(\mathrm{S}, \mathrm{R})$ are not discernable. Previous studies (Ellis et al. 1995) have demonstrated the association of this compound with other higher plant markers, both gymnosperm and angiosperm. Ellis et al. (1995) opined that this compound might originate during diagenesis from natural product precursors like bisabolene or curcumene owing to the similarity in the structures. It might also be possible that cadinane-related structures go through a series of reactions which include aromatization, opening of ring and giving rise to dihydro-ar-curcumene.

Cadalene is reported in the present sample. This compound is probably the diagenetic alteration of cadinane-related compounds (Loureiro and Cardoso 1990). The presence of cadalene indicates higher plant source (Dutta et al. 2011a, b). Isocadalene is probably present which forms a shoulder to cadalene and cadalene is more predominant with respect to isocadalene. Isocadalene/cadalene ratio is useful for understanding maturity of sediments and crude oils. Natural

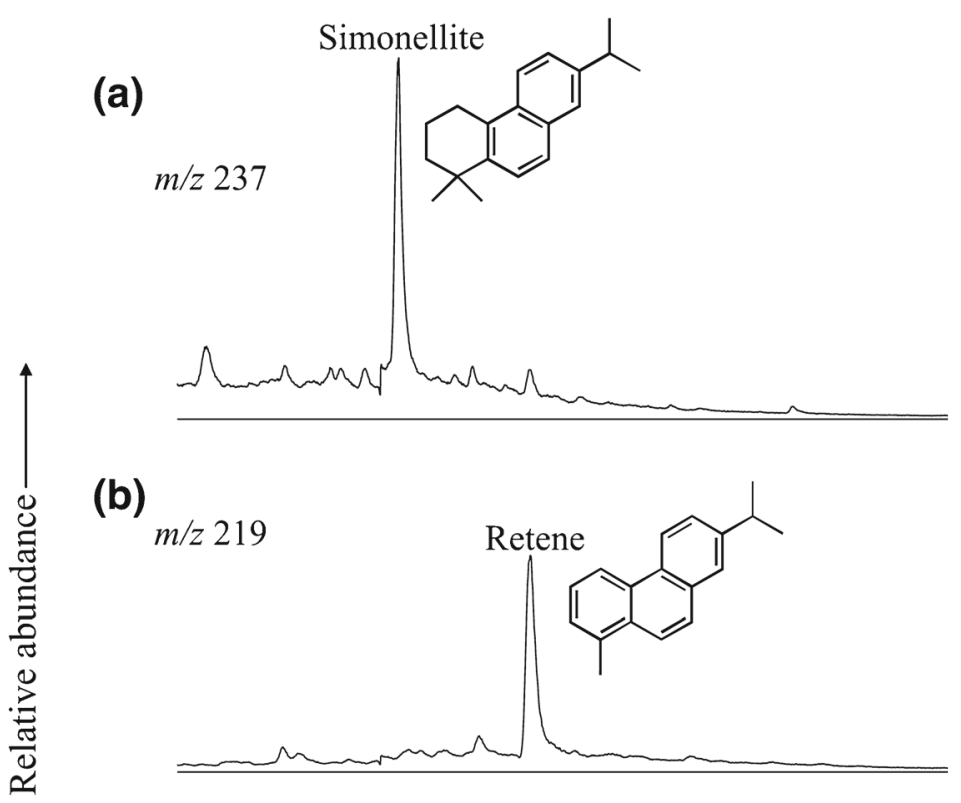

(c) $m / z 233$

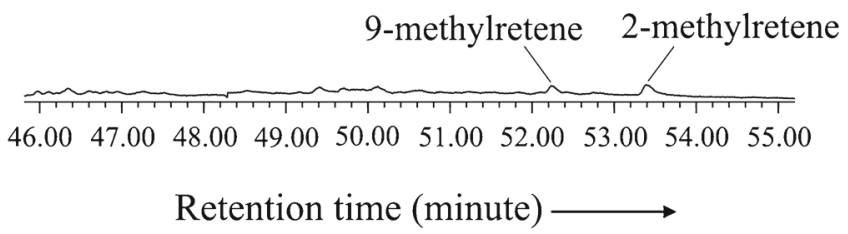

Figure 6. Partial mass chromatograms depicting the distributions of aromatic diterpenoids (a) simonellite $(m / z 237)$, (b) retene $(\mathrm{m} / z 219)$ and $(\mathbf{c})$ methylretene $(\mathrm{m} / z 233)$ in the aromatic fraction of condensate of Cretaceous age from a well, Jaisalmer basin, western India. 
products and laboratory experiments have shown that the abundance of isocadalene increases with depth/temperature (Alexander et al. 1994b).

Ionene $(\mathrm{m} / z$ 159) and methyl-ionene $(\mathrm{m} / z$ 173) have been recorded in the sample. They have been considered as degradation products of sesquiterpenoids or diterpenoids. These compounds are supposed to be alteration products of labdane-type diterpenoids (Yamamoto et al. 2006; Pereira et al. 2009; Menor-Salván et al. 2010).

\subsubsection{Diterpenoids}

The chromatograms of the following aromatic diterpenoids are depicted in figure 6 . Higher plant diterpenoid biomarkers are not recorded in the saturate fraction. This is probably because the saturate diterpenoids have been converted to their aromatic counterparts. This might be due to several factors. Firstly, thermal maturity might have played a role in the aromatization process. Also,

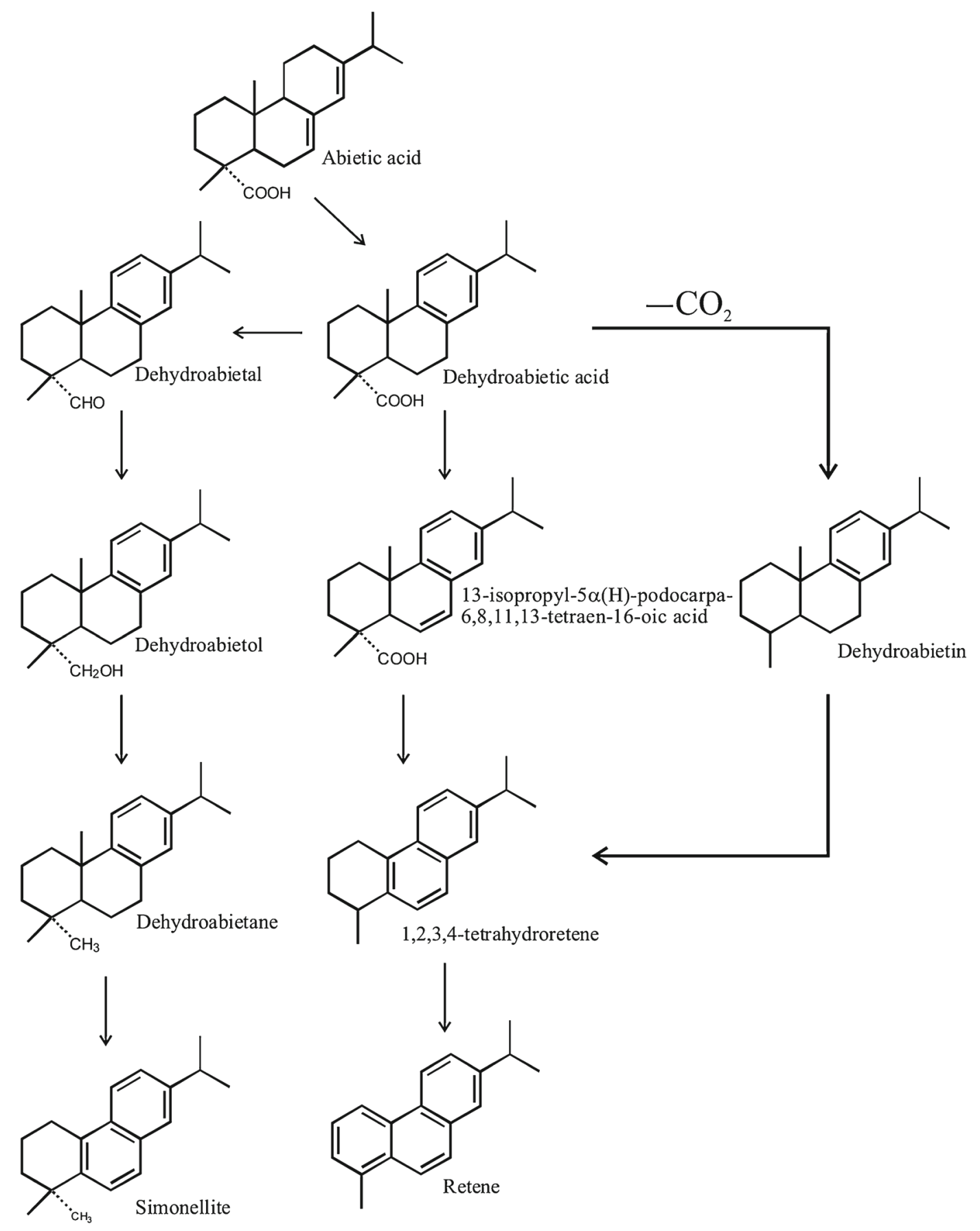

Figure 7. Possible mode of formation of simonellite and retene from abietic acid. Compounds enclosed in boxes are suggested intermediates (modified from Pereira and Rostad 1983). 
clay is known to catalyze molecular rearrangement reactions and it favours the aromatization of terrestrial plant terpenoids (Romero-Sarmiento et al. 2010).

Simonellite is believed to be derived from higher plant precursors, particularly conifers (Otto and Simoneit 2001). This compound is a diagenetic product of abietic acid (Otto et al. 1997). However, it has been argued that generation of simonellite from abietic acid is not favourable since abietic acid does not possess any gem-dimethyl group. Simonellite may originate from precursors bearing gem-dimethyl group such as compounds possessing abietane-skeleton or phyllocladane (Bastow et al. 2001). Further advancement in the diagenetic process transforms simonellite to retene through aromatization of ring $\mathrm{A}$ and removal of a methyl group from the same (Pereira and Rostad 1983).

Retene is generally related to coniferous precursors and considered as a diagenetic product of abietane-type diterpenoids like abietic acid (Otto and Simoneit 2001, 2002; Marynowski et al. 2007). Bryophytes might bear precursor compound or compounds of retene. Although the supposed precursors like abietic acid or terrestrial plant diterpenoids like phyllocladane have not been reported in bryophytes but rearranged abietanes and compounds with kaurane skeleton have been observed (Romero-Sarmiento et al. 2010). There have been proposals of retene being derived from phyllocladane when subjected to thermal alteration. This involves aromatization of the rings in phyllocladane and the generation of an isopropyl group (Alexander et al. 1987). Although several propositions have been made regarding the genesis of retene and numerous precursors are inferred, the most widely accepted view is its derivation from gymnosperm coniferous precursors. The possible mode of formation of simonellite and retene is presented in figure 7 . The assemblage of compounds that make up the condensate suggests that conifer has been the significant source into the organic matter.

Methylretene has also been observed although in very low abundance. Two peaks are discernable having the major fragments 233 and 248, signature of methylretene. The first peak corresponds to 9-methyl retene and the second peak corresponds to 2-methyl retene as compared with the data published by Bastow et al. (2001). Laboratory dehydrogenation experiments of simonellite have yielded retene as well as methylretene. It has been proposed that precursors having gemdimethyl group may generate methylretene by the shift of a methyl group (Bastow et al. 2001).

Finally, the presence of these sesquiterpenoids and diterpenoids in the studied sample clearly depicts that conifer-derived organic matter has contributed to the source biomass of the condensate. However, the predominance of normal alkanes ranging from $\mathrm{C}_{12}$ to $\mathrm{C}_{15}$ suggests that the organic matter was probably reworked by bacteria.

\section{Conclusions}

The present paper documents the organic geochemical characteristics of early Cretaceous condensate recovered from Jaisalmer basin, Rajasthan, India. The presence of aromatic sesquiterpenoids, for instance, dihydro-ar-curcumene, cadalene, ionene, are recorded which indicate higher plant precursors. Aromatic diterpenoids, simonellite, retene, and methylretene confirm the contribution of higher plants and also specify conifer source. The presence of normal alkanes dominant in the range of $\mathrm{C}_{12}-\mathrm{C}_{15}$ plausibly suggests reworking by bacterial biomass. The absence of saturate diterpenoids indicates that the conditions were hugely favourable for the aromatization process. Also, the presence of some distinctive compounds like diamondoids, isohexylalkylnaphthalenes and methylretene hints to the fact that rearrangement reactions, either triggered by thermal factors or microbial activities, were significant processes that determined the geochemistry of the condensate.

\section{Acknowledgements}

S Dutta is thankful to Department of Science and Technology (DST), India for providing financial support to procure GC-MS under FIST Programme. University Grants Commission (UGC) is also acknowledged for giving $\mathrm{PhD}$ scholarship to Sharmila Bhattacharya. The authors also thank Oil India Limited, Jodhpur, India for providing condensate sample from Jaisalmer basin, Rajasthan. IIT Bombay is acknowledged for providing infrastructure for research work. The authors also thank Prof. Ken Sawada and Prof. G V R Prasad for their valuable and constructive comments that enhanced the quality of the manuscript.

\section{References}

Alexander R, Kagi R I, Noble R and Volkman J K 1984 Identification of some bicyclic alkanes in petroleum; Org. Geochem. 6 63-70.

Alexander G, Hazai I, Grimalt J and Albaigés J 1987 Occurrence and transformation of phyllocladanes in brown coals from Nograd Basin, Hungary; Geochim. Cosmochim. Acta 51 2065-2073. 
Alexander R, Baker R W, Kagi R I and Warton B 1994a Cyclohexylbenzenes in crude oils; Chem. Geol. 113 $103-115$.

Alexander R, Kagi R I, Singh R K and Sosrowidjojo I B 1994b The effect of maturity on the relative abundances of cadalene and isocadalene in sediments from the Gippsland Basin, Australia; Org. Geochem. 21 115-120.

Ali Mansoori G 2007 Diamondoid molecules; Adv. Chem. Phys. 136 207-258.

Bastow T P, Singh R K, van Aarssen B G K, Alexander R and Kagi R I 2001 2-Methylretene in sedimentary material: A new higher plant biomarker; Org. Geochem. 32 1211-1217.

Botneva T A, Shulova N S, Nechaeva O L and Graizer E M 1990 Geochemical aspects of the genesis and accumulation of gas-condensate systems; Org. Geochem. 16 569-575.

Briggs J C 2003 The biogeographic and tectonic history of India; J. Biogeogr. 30 381-388.

Brocks J J and Pearson A 2005 Building the biomarker tree of life; Rev. Mineral. Geochem. 59 233-258.

Brooks J D, Gould K and Smith J W 1969 Isoprenoid hydrocarbons in coal and petroleum; Nature $\mathbf{2 2 2}$ $257-259$.

Chappe B, Albrecht P and Michaelis W 1982 Polar lipids of archaebacteria in sediments and petroleums; Science $\mathbf{2 1 7}$ 65-66.

Chatterjee S and Hotton III N 1986 The paleoposition of India; J. Southeast Asian Earth Sci. 1 145-189.

Dimmler A, Cyr T D and Strausz O P 1984 Identification of bicyclic terpenoid hydrocarbons in the saturate fraction of Athabasca oil sand bitumen; Org. Geochem. 7 231-238.

Dutta S, Mallick M, Kumar K, Mann U and Greenwood P F 2011a Terpenoid composition and botanical affinity of Cretaceous resins from India and Myanmar; Int. J. Coal Geol. 85 49-55.

Dutta S, Tripathi S M, Mallick M, Mathews R P, Greenwood P F, Rao M R and Summons R E 2011b Eocene outof-India dispersal of Asian dipterocarps; Rev. Palaeobot. Palynol. 166 63-68.

Ellis L, Singh R K, Alexander R and Kagi R I 1995 Identification and occurrence of dihydro-ar-curcumene in crude oils and sediments; Org. Geochem. 23 197-203.

Ellis L, Singh R K, Alexander R and Kagi R I 1996 Formation of isohexyl alkylaromatic hydrocarbons from aromatization-rearrangement of terpenoids in the sedimentary environment: A new class of biomarker; Geochim. Cosmochim. Acta 60 4747-4763.

Fang C, Xiong Y, Liang Q and Li Y 2012 Variation in abundance and distribution of diamondoids during oil cracking; Org. Geochem. 47 1-8.

Föllmi K B 2012 Early Cretaceous life, climate and anoxia; Cretaceous Res. 35 230-257.

Fowler M G and Douglas A G 1984 Distribution and structure of hydrocarbons in four organic-rich Ordovician rocks; Org. Geochem. 6 105-114.

Fowler M G, Abolons P and Douglas A G 1986 Monocyclic alkanes in Ordovician organic matter; Org. Geochem. 10 $815-823$.

Hwang R J and Teerman S C 1988 Hydrocarbon characterization of resinite; Energy and Fuel 2 170-175.

Hunt J M 1996 Petroleum Geochemistry and Geology; W.H. Freeman and Co., New York, 743p.

Kissin Y V 1990 Catagenesis of light cycloalkanes in petroleum; Org. Geochem. 15 575-594.

Krishna J 1987 An overview of the Mesozoic stratigraphy of the Kachchh and Jaisalmer basins; J. Palaeontol. Soc. India 32 136-149.
Li M, Larter S R and Taylor P 1995 A new hypothesis for the origin of pristane involving derivation from methyltrimethyltridecylchromans (MTTC'S) formed during diagenesis from chlorophyll and alkylphenols; Org. Geochem. 23 159-167.

Loureiro M R B and Cardoso J N 1990 Aromatic hydrocarbon in the Paraiba Valley oil shale; Org. Geochem. 15 351-359.

Marynowski L, Zatoń M, Simoneit B R T, Otto A, Jedrysek M O, Grelowski C and Kurkiewicz S 2007 Composition, sources and depositional environments of organic matter from the Middle Jurassic clays of Poland; Appl. Geochem. 22 2456-2485.

Marzi R, Torkelson B E and Olson R K 1993 A revised carbon preference index; Org. Geochem. 20 1303-1306.

Menor-Salván C, Najarro M, Velasco F, Rosales I, Tornos F and Simoneit B R T 2010 Terpenoids in extracts of Lower Cretaceous ambers from the Basque-Cantabrian Basin (El Soplao, Cantabria, Spain): Paleochemotaxonomic aspects; Org. Geochem. 41 1089-1103.

Otto A and Simoneit B R T 2001 Chemosystematics and diagenesis of terpenoids in fossil conifer species and sediment from the Eocene Zietz formation, Saxony, Germany; Geochim. Cosmochim. Acta 65 3505-3527.

Otto A and Simoneit B R T 2002 Biomarkers of Holocene buried conifer logs from Bella Coola and north Vancouver, British Columbia, Canada; Org. Geochem. 33 1241-1251.

Otto A, Walther H and Püttmann W 1997 Sesqui- and diterpenoid biomarkers preserved in Taxodium-rich Oligocene oxbow lake clays, Weisselster basin, Germany; Org. Geochem. 26 105-115.

Peters K E, Walters C C and Moldowan J M 2005 The Biomarker Guide. Volume 2: Biomarkers and Isotopes in the Petroleum Exploration and Earth History; Cambridge University Press, Cambridge, UK, 1155p.

Pereira W E and Rostad C E 1983 Terpenoid marker compounds derived from biogenic precursors in volcanic ash from Mount St. Helens, Washington; Geochim. Cosmochim. Acta 47 2287-2291.

Pereira R, Carvalho I S, Simoneit B R T and Azevedo D A 2009 Molecular composition and chemosystematic aspects of Cretaceous amber from the Amazonas, Araripe and Recôncavo basins, Brazil; Org. Geochem. 40 863-875.

Petrov A A, Arefjev O A and Yakubson Z V 1974 Hydrocarbons of adamantane series as indices of petroleum catagenesis process; In: Advances in Organic Geochemistry (eds) Tissot B and Bienner F, Editions Technip, Paris, France, pp. $517-522$.

Philp R P and Gilbert T D 1986 Biomarker distributions in Australian oils predominantly derived from terrigenous source material; Org. Geochem. 10 73-84.

Powell T G and McKirdy D M 1973 Relationship between ratio of pristane to phytane, crude oil composition and geological environment in Australia; Nature 243 37-39.

Romero-Sarmiento M F, Riboulleau A, Vecoli M and Versteegh G J M 2010 Occurrence of retene in upper Silurianlower Devonian sediments from North Africa: Origin and implications; Org. Geochem. 41 302-306.

Shanmugam G 1985 Significance of coniferous rainforests and related organic matter in generating commercial quantities of oil, Gippsland Basin, Australia; Am. Assoc. Petrol. Geol. Bull. 69 1241-1254.

Snowdon L R and Powell T G 1982 Immature oil and condensate: Modification of hydrocarbon generation model for terrestrial organic matter; Am. Assoc. Petrol. Geol. Bull. 66 775-788.

Thompson K F M 1987 Fractionated aromatic petroleums and the generation of gas-condensates; Org. Geochem. 11 $573-590$. 
Valdiya K S 2010 The making of India: Geodynamic evolution; Macmillan Publishers, New Delhi, India, 816p.

Verma D, Jadhav G N, Biswal T K, Jena S K and Sharma N 2012 Characterization of hydrocarbon bearing fluidinclusion in sandstones of Jaisalmer basin, Rajasthan: A preliminary approach; J. Geol. Soc. India 80 505-514.

Wang T G, Simoneit B R T, Philp R P and Yu C P 1990 Extended 8b (H) - Drimane and 8,14-Secohopane Series in a Chinese Boghead Coal; Energy and Fuels 4 177-183.
Weston R J, Philp R P, Sheppard C M and Woolhouse A D 1989 Sesquiterpanes, diterpanes and other higher terpanes in oils from the Taranaki basin of New Zealand; Org. Geochem. 14 405-421.

Yamamoto S, Otto A, Krumbiegel G and Simoneit B R T 2006 The natural product biomarkers in succinite, glessite and stantienite ambers from Bitterfield, Germany; Rev. Palaeobot. Palynol. 140 27-49.

http://www.dghindia.org/23.aspx, Monday, July 08, 2013.

MS received 29 August 2013; revised 26 February 2014; accepted 28 February 2014 